\title{
Comparative analysis of equipment and research the superfine grinding process of titanium dioxide and quinacridone red suspensions in the bead mill
}

\author{
Kateryna Hrininh, Ruslan Hordeichuk, Oleksii Gubenia
}

National University of Food Technologies, Kyiv, Ukraine

Keywords:

Grinding

Beads

Mill

Pharmacy

Cosmetics

Suspension

Article history:

Received

25.01.2018

Received in revised

form 27.05.2018

Accepted 29.06.2018

\section{Corresponding \\ author:}

Kateryna Hrininh

E-mail:

neackriss@

gmail.com

\section{Abstract}

Introduction. Analytical and experimental research was conducted to improve the process and equipment for the superfine grinding of medicinal and cosmetic preparations.

Materials and methods. On the basis of modern scientific literature and own experience was given a comparative analysis of modern equipment for ultra-fine grinding. In the investigation are used suspensions of titanium dioxide and quinacridone red 122 with the vaseline oil.

Results and discussion. Among the recommended installations, the most versatile, productive, compact, energy saving, with high degree for grinding (up to 1 microns), effective in the process of dispersion and homogenization, have a simple constructive solution are bead mills.

When grinding titanium dioxide over a period of 0 to 30 minutes, the power increases from 205 to $209 \mathrm{~W}$. The temperature of the suspension is from 21.9 to $23.4{ }^{\circ} \mathrm{C}$, the density increases from 889 to $1176 \mathrm{~kg} / \mathrm{m}^{3}$, and the particle size decreases from more than $100 \mu \mathrm{m}$ to $10 \mu \mathrm{m}$. The most intensive grinding in the first 5 minutes of the process. When the quinacridone red 122 is grinded, the power is increased from 205 to $210 \mathrm{~W}$, the temperature of the suspension is from 22.4 to $24.3{ }^{\circ} \mathrm{C}$, the density increases from 870 to 952 $\mathrm{kg} / \mathrm{m} 3$, and the particle size decreases from more than $60 \mu \mathrm{m}$ to $2 \mu \mathrm{m}$, while the most intensive grinding occurs in the first 5 minutes of the process.

Conclusions. Among the recommended installations, the most optimal and productive are bead mills. It is recommended to carry out the grinding process on the bead mills periodically with the circulation of the suspension with the obligatory cooling.

DOI:

$10.24263 / 2310-$

1008-2018-6-1-11 


\section{Introduction}

In the modern production of pharmaceuticals and cosmetics, a high degree of grinding of the raw material for further use is of great importance. When the technological process of the produce of the soft dosage forms is implemented, it is necessary to distribute and grind fine dispersed solids in a liquid medium, because during storage and transport of the starting material, the particles stick together forming the conglomerates, and the powder particles have an irregular shape and a non-uniform particle size distribution [12] and such raw materials can't give the product the necessary efficiency and quality. Therefore, the obligatory stage in the production of ointments, liniments, gels and pastes is dispersing [2]. This task perfectly solve the bead mills, which are used for grinding a wide range of different products, including pharmaceutical and cosmetic industries.

\section{Exposition}

\section{Comparative analysis of existing equipment for superfine grinding}

For today, there are such type of machines for superfine grinding: bead mills, three-roller mills, colloid mills, jet mills, vibrating mills, planetary mills.

Three-roll mills. Rolls that are rotated toward at different speeds ensure the product moves from a roll to a roll and increases friction between them. Rolls are made of porcelain, basalt or metal [3]. To maintain the optimum temperature of the product rolls are make hollow for serving the coolant inside. Degree of material grinding is to $3 \mu \mathrm{m}$ (index taken from industrial working equipment). In the cosmetic industry it is used for grinding of the pigmentary pastes, creams. In the pharmaceutical industry - for the production of the ointments, liniments, gels, pastes [3, 13].

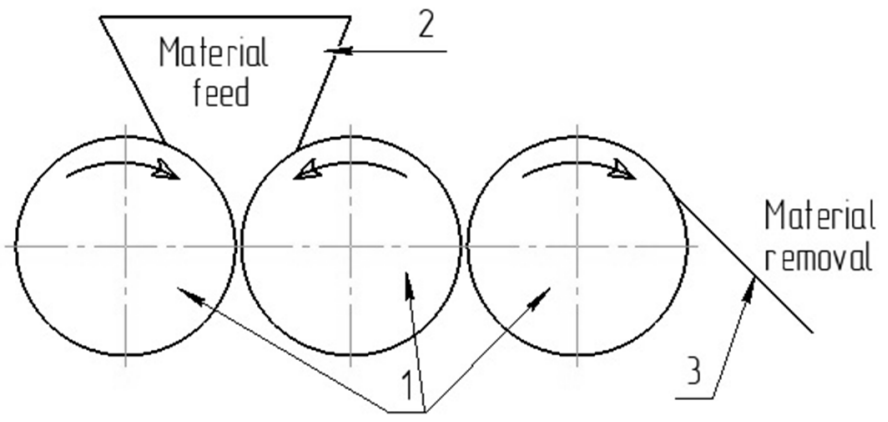

Figure 2. Three-roll mill:

1-rolls; 2 - bunker; 3 - shooting knife

Advantages: magnet-based safety devices; possibility of embedding into an industrial continuous production line; suitable for the processing of very common materials that are prone to sticking or containing sticky inclusions; compactness. 
Disadvantages: not intended for grinding dry ingredients; intensive and uneven wear of working surfaces of rolls and a knife; relatively low specific productivity; the probability of bias shaft due to uneven tightening springs; when the maximum fineness is reached, the productivity decreases [13].

Bead mill. The bead mill consists of two parts: a grinding chamber, in which the beads are loaded together with the components of the mixture, and the rotor, which rotates the entire system. The grinding process proceeds between the individual bead particles which are in contact with each other, as well as between the beads and the rotor or the walls of the container. The size of the crushed product can reach less than 1 microns. In the cosmetic industry they are used for grinding of the pigmentary pastes, creams. In the pharmaceutical industry - for the production of the ointments, pastes, gels, liniments $[10,11,13]$.

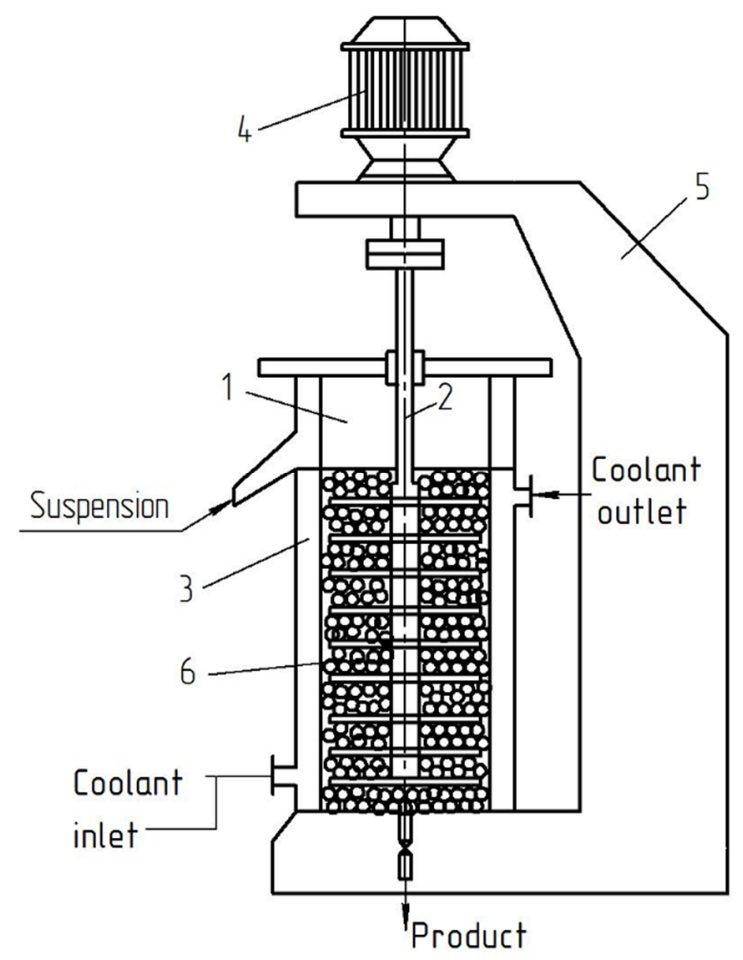

Figure 1. Bead mill:

1 - cylinder, 2 - disk rotor, 3 - shirt, 4 - engine, 5 - bedplate, 6 - beads.

Advantages: easy maintenance; reliability and safety of work; versatility; high performance; invariably quality of grinding; simplicity of construction; possibility of embedding into an industrial continuous production line; effective in the process of dispersing, homogenizing and grinding simultaneously.

Disadvantages: great power consumption; a small coefficient of useful action $-15 \%$; not economical consumption of water and detergent to prepare the equipment for work; burning and "burning out" of the suspension in case of insufficient cooling. [9, 10, 13]. 


\section{- Processes and Equipment -}

Vibration mills. The grinding is carried out using a special vibrating device, which is on the same axis with the electric motor, the ball drum vibrates. The balls are made from a porcelain, hard alloys or steel. The drum is full with balls for $80-90 \%$. The size of the crushed product is $1-5$ microns. They are used for fine-grained crushing of materials of low strength $[6,10]$.

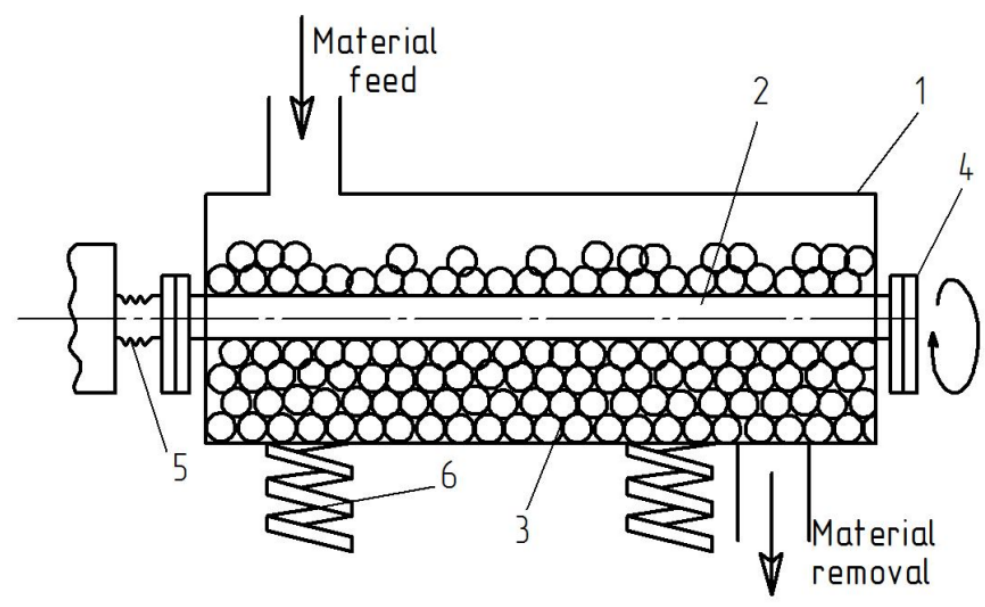

Figure 3. Vibration mill:

1 - housing, 2- vibrator, 3 - milling balls, 4 - out of balance weight, 5 - flexible coupling to drive motor, 6 - spring mounting.

Advantages: high dispersion and homogeneity of the particle size of the product are achieved very quickly.

Disadvantages: not suitable for grinding powders sticky and viscous pastes and thermolabile materials; low productivity (up to $1 \mathrm{t} / \mathrm{h}$ ); rapid wear of grinding bodies; hard working conditions $[6,10]$.

Colloidal mills. A lot of designs of the mills are offered. For preventing the adhesion of particles, the milling is done in the presence of a dispersing medium. The size of the crushed product is less than 0.4 microns. In the pharmaceutical industry they are used for the produce of liniments, ointments, pastes. In the chemical industry - for the crushing of some mineral pigment [12].

Advantages: effective emulsification and dispersion process.

Disadvantages: high wear of working elements; little knowledge of the process [13].

Jet mills. An energy source (a compressed gas or a steam) at expansion in the nozzles acquires a high speed, which sometimes reaches several hundred meters per second. The material particles are crushed as a result of a collision between themselves when streams jets intersect, as well as strokes and abrasion on the wall of the chamber $[6,11]$. The size of the crushed product is 2-5 microns. In the pharmaceutical industry are used to obtain superfine powders from expensive components $[12,13]$ 


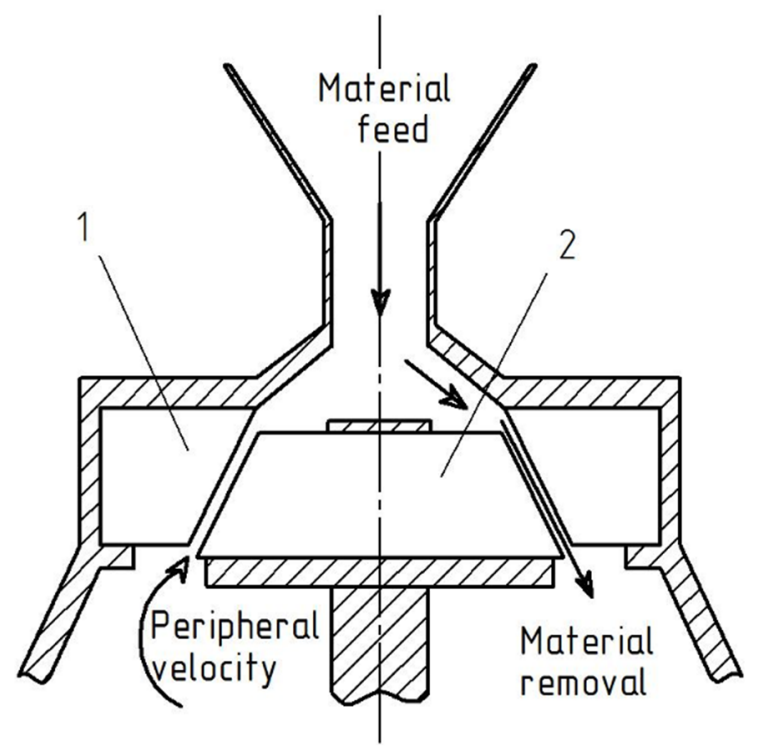

Figure 4. Colloidal mill:

1- stator, 2 - rotor.

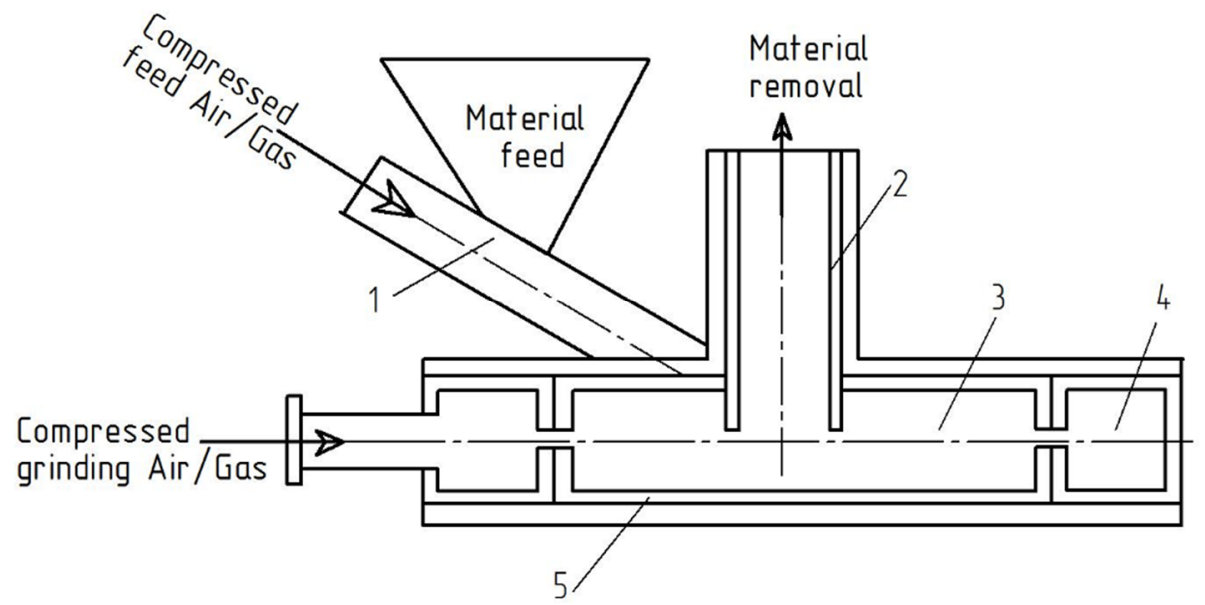

Figure 5. Jet mill:

1 - Venturi eductor, 2 - vortex finder, 3 - grinding chamber, 4 - grinding Air/Gas manifold, 5 - replaceable liners.

Advantages of the jet mill: the grinding elements of the mill practically do not wear out, and therefore don 't add impurities to the finished product; longevity of equipment; provides high purity powders with a predominantly oval form of particles; the material in the process of grinding doesn't change its initial temperature, which allows processing of thermolabile; minimal product loss. 


\section{- Processes and Equipment -}

Disadvantages of the jet mill: high energy consumption resulting in high energy consumption of the process; necessary to uniform supply of material and maintenance of constant aerodynamic mode of operation; necessary provision of additional equipment (air separator); danger of work $[6,12]$

Planetary mills. The principle of the work is to rotate 3-4 drum around to the central axis and around its own axis in the opposite direction of rotation of the rotor (central axis) of the mill. The size of the crushed product is less than 4-6 microns. Used mainly in laboratories for scientific research, as well as in industries where small amounts of fine powders are required $[1,12]$.

Advantages: high specific productivity.

Disadvantages: high wear of working elements; difficulty with continuous loading and unloading of material $[1,4,12]$.

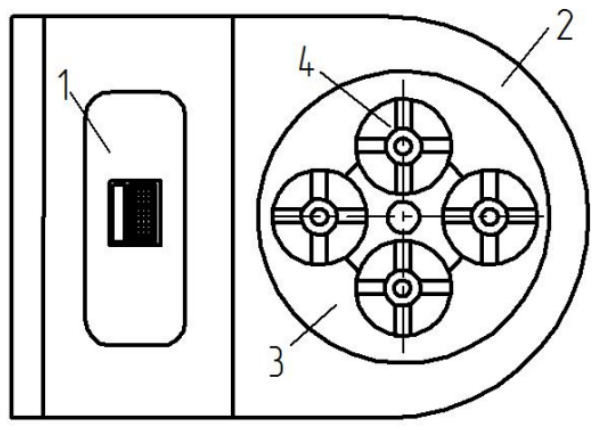

Figure 5. Planetary mill:

1 - control panel, 2 - safety switch, 3 - planetary disk, 4 - ball mill jar.

Among the recommended mills, the most versatile, compact, energy saving, capacity, with the possibility of embedding to an industrial continuous production line, with high grinding rates (up to $1 \mu \mathrm{m}$ ), effective in the process of dispersion and homogenization, have a simple constructive solution, are bead mills. Despite its disadvantages, the bead mill is one of the most popular mill using in the cosmetic industry to grind pigment pastes and creams, and in the pharmaceutical industry - for the production of ointments, gels, pastes, liniments.

\section{Materials and method}

\section{Materials}

The following materials were used for the research: Vaseline oil perliquidum pharmaceutical, white pigment titanium dioxide (food additive E171) pharmaceutical, pigment quinacridone red Red 122. 


\section{- Processes and Equipment -}

Vaseline oil perliquidum pharmaceutical - mineral oil, a mixture of liquid hydrocarbons of petroleum distillate. The quality of Vaseline oil is characterized by its color. It is determined by the Saybolt scale. The dark one is "- 16", the light one is $30[5,6]$.

Vaseline oil in pharmaceutics is used as a basis for creating multi-component ointments and creams, injectable suspensions, as a solvent for some medicines, and as a separate medicinal product. In the cosmetic industry, oil is used as a base for the preparation of a wide range of creams, but only if it has been multistage cleaned and completely cleared of foreign smell and impurities. Also, it is used in the production of decorative cosmetics $[5,6]$.

Appearance: colorless, clear, oily liquid. Virtually insoluble in water, slightly soluble in ethanol $96 \%$, mixed with carbohydrates. Color (Saybolt) -+30 . The kinematic viscosity at $40{ }^{\circ} \mathrm{C}$ is $11-15 \mathrm{CST}$. Dynamic viscosity at $20^{\circ} \mathrm{C}$ is $33-45 \mathrm{MPa} \cdot \mathrm{s}$. The relative density at 20 ${ }^{\circ} \mathrm{C}$ is $818-880 \mathrm{~kg} / \mathrm{m}^{3}[5,6]$.

Titanium dioxide (titanium white, E171) is a white pigment. In the pharmaceutical industry, titanium dioxide is used for high chemical cleanliness to provide a high whitening and crusting effect. It is used for cosmetic products for giving white color and light tightness. In addition, it is used for the preparation of concentrated pigment pastes for various types of lipsticks, lip glosses, nail polishes, powders, tonal creams and other decorative products [5, 6].

Appearance: powder from white to slightly colored. The residue on the sieve with a mesh of $45 \mu \mathrm{m}$ is $0.08 \%$. Bulk density of $82 \mathrm{~kg} / \mathrm{m}^{3}$; Specific density $4000 \mathrm{~kg} / \mathrm{m}^{3}$. Insoluble in water and organic solvents $[5,6]$.

Quinacridone red Red 122. Universal dry pigment, which has a stable purple hue among the violet-red pigments. It also has an increased stability of flocculation, good flowability. Used in the cosmetic industry for the preparation of concentrated pigment pastes for various types of lipsticks, lip glosses, nail polish [5, 6].

Appearance: powder of bright red color with a blue hue. Specific density is $1460 \mathrm{~kg} / \mathrm{m}^{3}$; bulk density $540 \mathrm{~kg} / \mathrm{m}^{3}$; The residue on the sieve with a mesh of $320 \mu \mathrm{m}$ is $23,4 \%$; the average particle size is $0,09 \mu \mathrm{m}$; specific surface area of $59 \mathrm{~m}^{2} / \mathrm{g}$. Resistant to acids, alkalis, water, organic solvents $[5,6]$.

\section{Methods}

Expiremental instalations were used:

Bead laboratory mill. Equipped with three capasity (glasses) with a shirt for water cooling and a sampler on the lid of a glass with a sieve cartridge. The rotor consists of a shaft on which 4 guide discs with 4 symmetrically located holes with a diameter of $1 \mathrm{~cm}$ are fixed. The working members are a glass bead that has a diameter of $2 \mathrm{~mm}$. The motor operates at $380 \mathrm{~V}$ with a current of $1.0 \mathrm{~A}$ with a rotor speed of $1350 \mathrm{rpm}[7,13,14]$.

Pyrometer is a non-contact digital thermometer. Infrared principle of action. The temperature range is from $-50{ }^{\circ} \mathrm{C}$ to $+330^{\circ} \mathrm{C}$ (from $-58^{\circ} \mathrm{F}$ to $626^{\circ} \mathrm{F}$ ). The accuracy is $\pm 1.5 \%$ $[9,12]$.

Grindometer "Klin" is intended for the analysis of the particle size and agglomerates in determining the degree of grinding when testing pigmented suspension materials in different measuring ranges. The measuring range is from 0 to $100 \mu \mathrm{m}$. The scale division is $10 \mu \mathrm{m}$. The limit of the permissible absolute error is $\pm 10 \mu \mathrm{m}$. Dimensions: measuring plate $-175 \times 35 \times 20$; the scraper is $60 \times 40 \times 6 \mathrm{~mm}[9,12]$.

The current clamps is a model of a multimeter with clamps, which opens up to a width of $5 \mathrm{~cm}$. Clamps work on the principle of electromagnetic induction. 


\section{- Processes and Equipment -}

With it, you can measure AC and DC voltage, resistance, temperature, test diodes, ring connections, measure frequency. Equipped with a liquid crystal display with a resolution of $3 \frac{1}{2}$, which displays the results of all measurements $[9,14]$.

The scheme of the experimental setup is shown in Figure1 $[7,8,14]$.
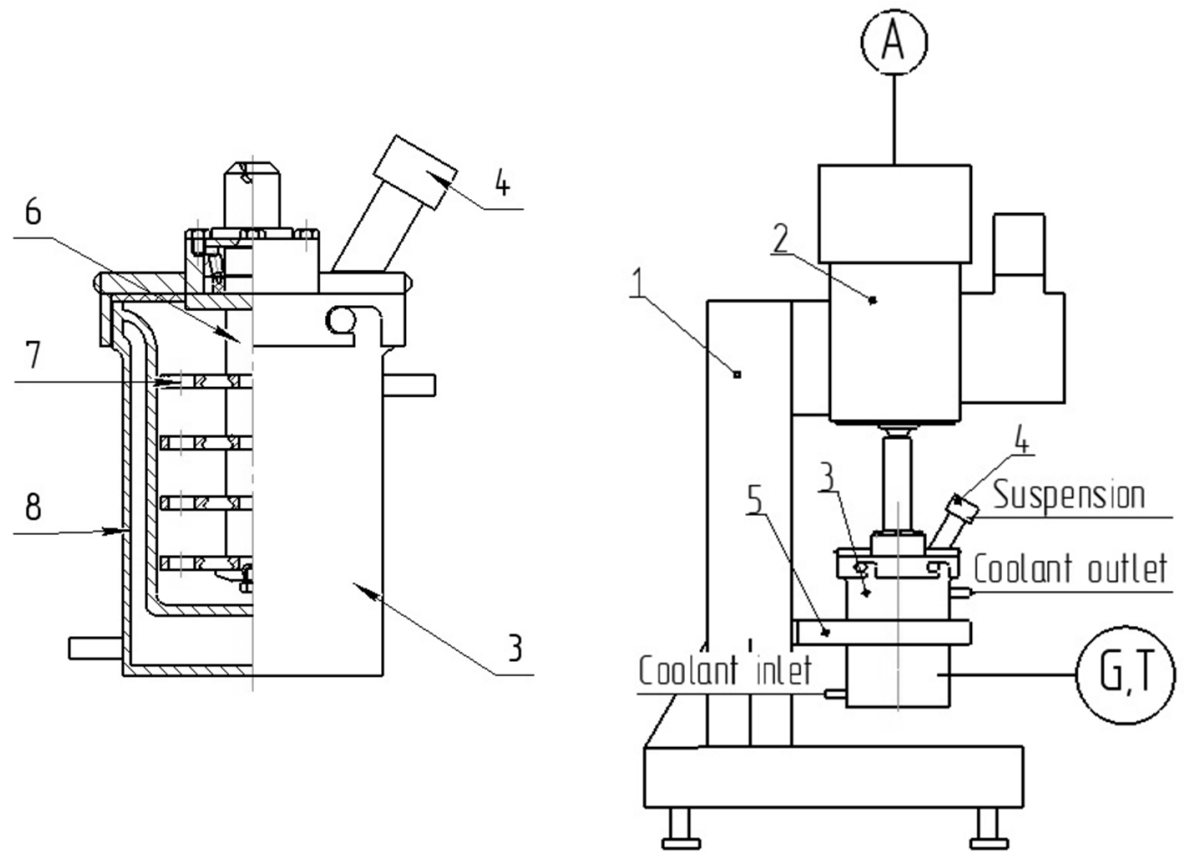

Figure 6. The scheme of the experimental instalation:

1 - bedplate; 2 - motor; 3 - glass; 4 - sampler; 5 - clamp.

The preparation of the samples was as follows: in three clean glasses with a volume of $250 \mathrm{ml}$ hung pigments and Vaseline oil according to the following recipe $[9,12]$ :

Composition A: Vaseline oil - $250 \mathrm{~g}$;

Composition B: titanium dioxide $50 \mathrm{~g}$, Vaseline oil $200 \mathrm{~g}$;

Composition C: Red $122-30$ g, Vaseline oil - $200 \mathrm{~g}$.

There were weighed on an analytical scale with a precision of $0.01 \mathrm{~g}$. The compositions $\mathrm{B}$ and $\mathrm{B}$ were mixed on a agitator.

Composition A was tested for temperature only. Compositions $\mathrm{B}$ and $\mathrm{C}$ were tested for the temperature of the suspension by means of a pyrometer, the particle size with a "Klin" grindometer.

After testing, the compositions took turns taking part in the experiment $[9,12]$.

The bead mill operated in a batch mode with cooling, after each experiment the installation was washed. The samples were analyzed and the instruments readings were taken every 5 minutes for 30 minutes. The obtained samples were analyzed for the degree of grinding by a grindometer, the pyrometer measured the temperature of the suspension, and the amperage at three phases was measured with a current clamps [2, 13]. 


\section{Results and discussion}

The results of the research are shown in the graphs below (Figures 7-11).

Consequently, with increasing grinding time for both components, power, temperature and density increase. The greatest growth is observed in the site from 0 to 15 minutes.

When grinding titanium dioxide over a period of time from 0 to 30 minutes, power increases from 205 to $209 \mathrm{~W}$ (Figure 7), that is, from 20.5 to $33.2 \mathrm{~W}$ (Figure 8) is consumed relatively the power that is consumed to drive the grinding bodies (beads). At the beginning of the experiment, the particle size and agglomerate were at an average of $100 \mu \mathrm{m}$, and at the end of the experiment, $10 \mu \mathrm{m}$ (Figure 9). The most intense reduction in the size of the particles occurred in the first 5 minutes of the experiment (the particles were grinding from $100 \mu \mathrm{m}$ to $50 \mu \mathrm{m}$ ). During the process, the temperature rises to an average of $21.9^{\circ} \mathrm{C}$ to 23.4 ${ }^{\circ} \mathrm{C}$ for 30 minutes of the experiment (Figure 10). The greatest increase in temperature occurred in the interval from 15 to 20 minutes, where the temperature increase from 22.3 to $22.8^{\circ} \mathrm{C}$, and also where the suspension particles were grinded from 25 to $20 \mu \mathrm{m}$. This can be explained by the fact that the suspension has the highest density after grinding $-1176 \mathrm{~kg} / \mathrm{m}^{3}$ (Figure 11), as well as the largest size of agglomerates at the beginning of the experiment (more than $100 \mu \mathrm{m})[5,6,8]$.

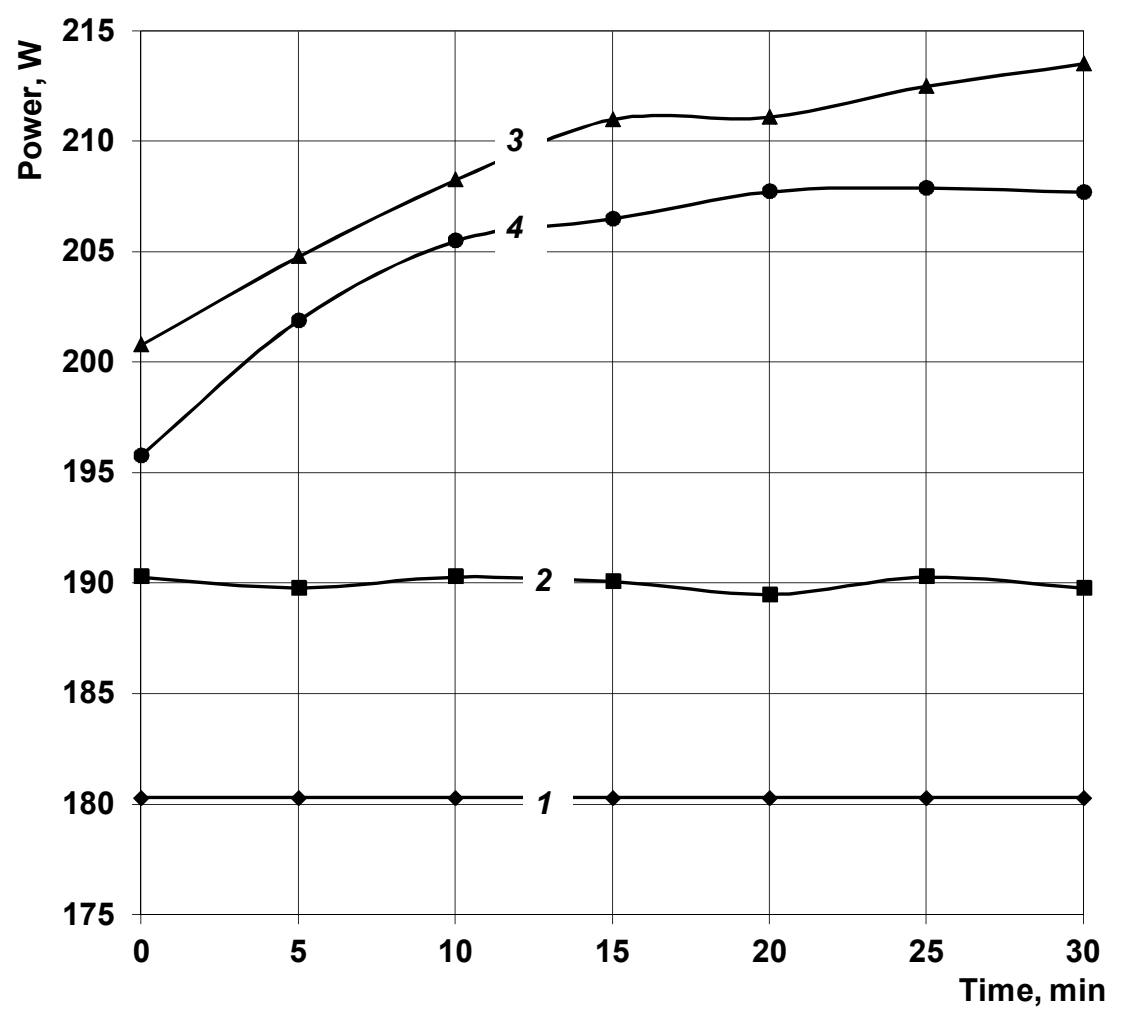

Figure 7. Effect of grinding time in power:

1 - Without glass; 2 - Vaseline oil; 3 - Titanium dioxide; 4 - Red 122 

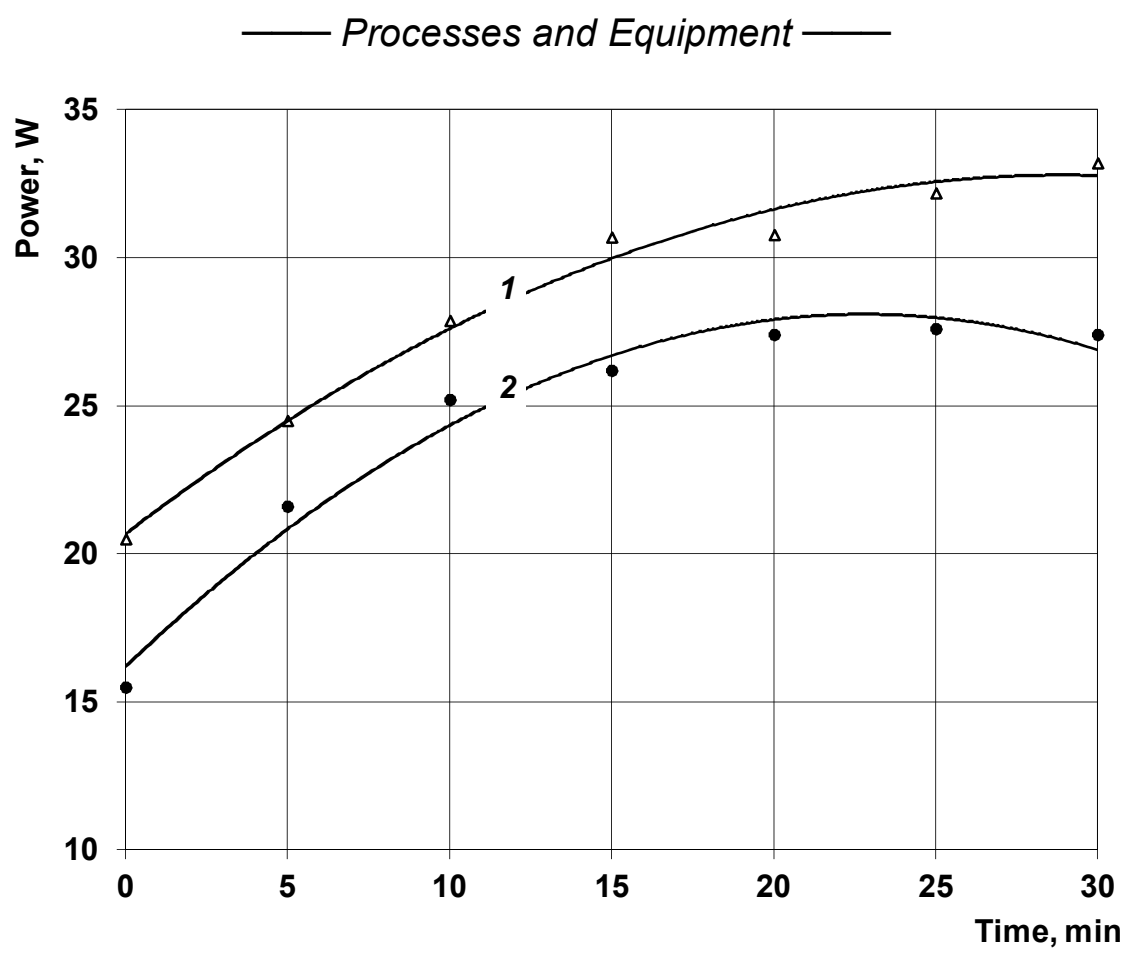

Figure 8. Total amount of power for mixing and grinding:

1 - Titanium dioxide; 2 - Red 122

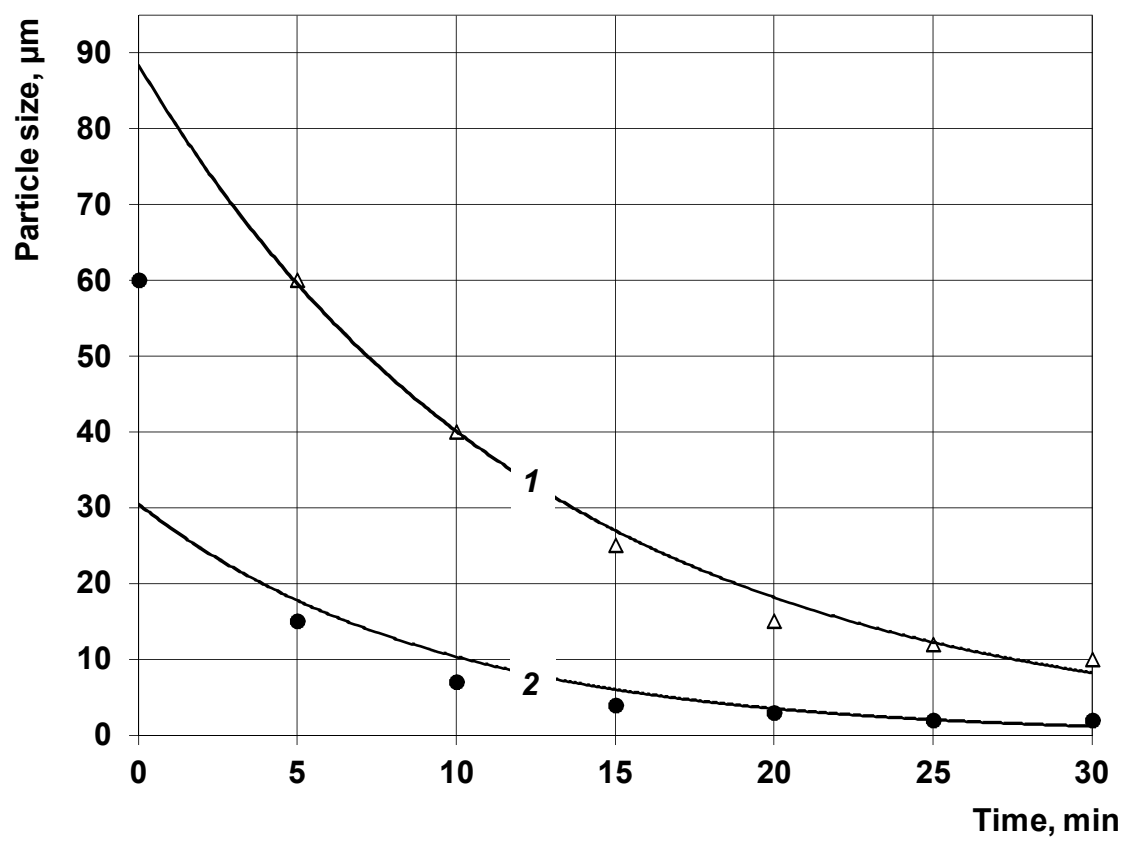

Figure 9. Change in particle size, $\mu \mathrm{m}$ :

1 - Titanium dioxide; 2 - Red 122 


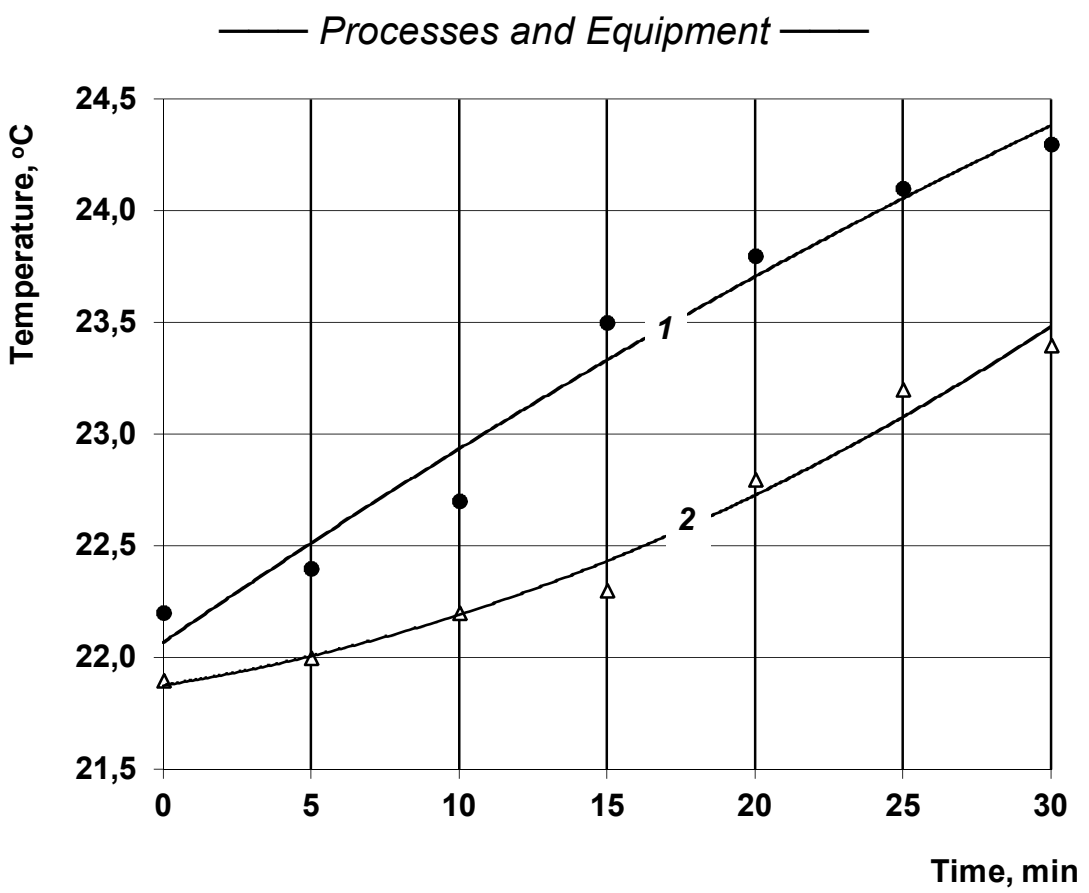

Figure10. Change in temperature of the suspension, ${ }^{\circ} \mathrm{C}$ :

1 - Titanium dioxide; 2 - Red 122

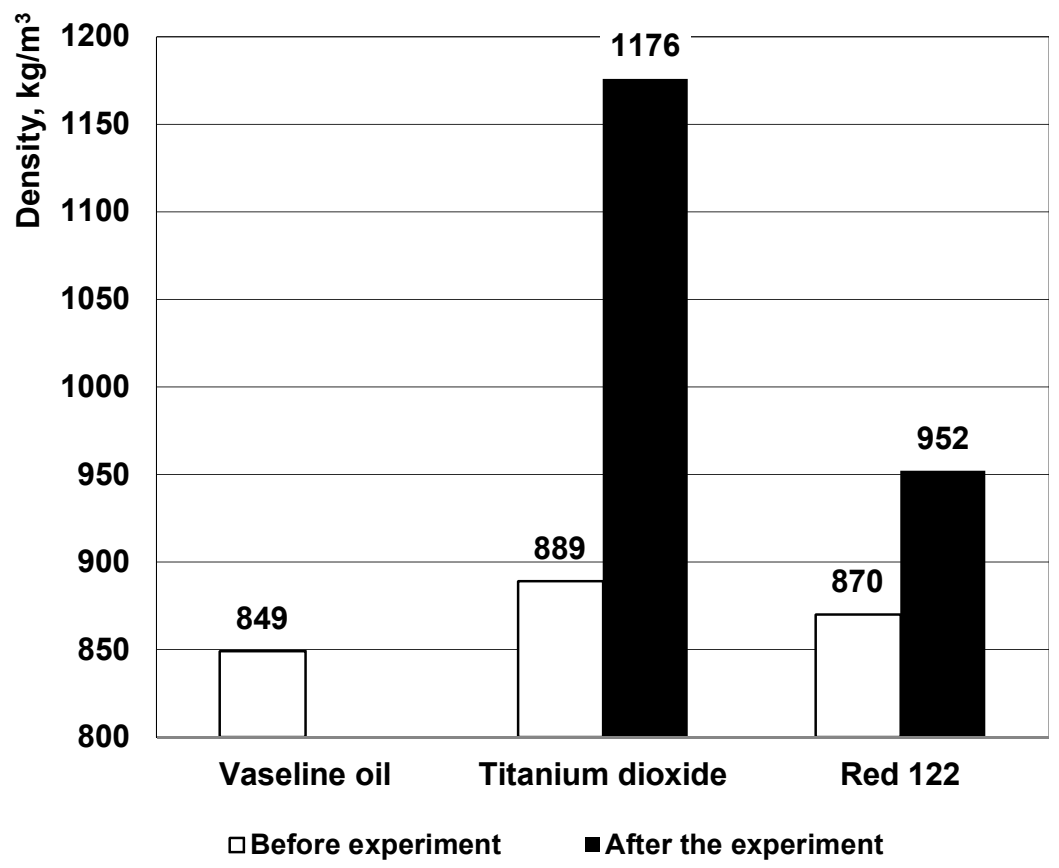

Figure 11. Change in suspension density, $\mathrm{kg} / \mathrm{m}^{3}$ 


\section{- Processes and Equipment -}

When grinding a suspension of quinacridone red Red 122 over a period of time from 0 to 30 minutes, power increases from 195.8 to $207.9 \mathrm{~W}$ (Figure 7), that is, from 15.5 to 27.6 $\mathrm{W}$ (Figure 8) is consumed relatively the power that is consumed to drive the grinding bodies (beads). The particle size was $60 \mu \mathrm{m}$ on average and $2 \mu \mathrm{m}$ at the end of the experiment (Figure 9). At the end of the experiment, there was almost no grinding (from 4 to $2 \mu \mathrm{m}$ in 15 minutes). The temperature increased on average from $22.2{ }^{\circ} \mathrm{C}$ to $24.3{ }^{\circ} \mathrm{C}$, which is much higher than the data when grinding a suspension of titanium dioxide (Figure 10). The highest temperature increase occurred over a period of 10 to 15 minutes, when the temperature increase from 22.7 to $23.5^{\circ} \mathrm{C}$, where the size of the suspension particles decreased from 7 to $4 \mu \mathrm{m}$. This can be explained by the fact that Red 122 has a greater bulk density $\left(540 \mathrm{~kg} / \mathrm{m}^{3}\right)$ than titanium dioxide $\left(82 \mathrm{~kg} / \mathrm{m}^{3}\right)$ and crystal lattice strength due to a different chemical formula, which may also be due to the density of the suspension $[5,6,8]$.

During the experiment, the density of the suspension changed (Figure 11). Thus, the average density of Vaseline oil (according to the manufacturer) is $849 \mathrm{~kg} / \mathrm{m}^{3}$. The density of the titanium dioxide suspension to the experiment is an average of $889 \mathrm{~kg} / \mathrm{m}^{3}$, and the density of the quinacridone red Red 122 before the experiment was an average of $870 \mathrm{~kg} / \mathrm{m}^{3}$ (Figure 11). After the experiment, the density of the titanium dioxide suspension amounted to 1176 $\mathrm{kg} / \mathrm{m}^{3}$, and the average density of the suspension of quinacridone red was $952 \mathrm{~kg} / \mathrm{m}^{3}$. The density of the titanium dioxide suspension increased during the experiment by $287 \mathrm{~kg} / \mathrm{m}^{3}$, and the quinacridone red $-82 \mathrm{~kg} / \mathrm{m}^{3}$ (Figure 11) $[5,6,8]$.

For the job of a bead mill with Vaseline oil, which is used in this case as a lubricant to avoid wear of the plant, it consumes from 188.9 to $190.3 \mathrm{~W}$.

\section{Conclusion}

Consequently, with increasing time of grinding, both suspensions increase power, temperature, and density and decrease the size of particles. Basically, the most intense changes occur during the first 15-20 minutes of the experiment, where there is an intense reduction of particles of solid material.

This is due to the fact that initially in the suspension are not only individual particles of solids, but also agglomerates that are grinding quite easily. When the size of the particles of the material decreases, the strength of the particles increases, so the more power is consumed and therefore more energy is consumed to overcome the forces of mutual adhesion of solid particles with external forces. In addition, reducing the size of the particles leads to the dissipation of energy in the form of heat and goes to the movement of particles inside the body, without causing its destruction. Also, the smaller the size of the particles that can be achieved, the larger the area of the newly formed surface and, accordingly, increasing the density of the suspension. Accordingly, the amount of energy that needs to be applied before grinding the solids suspension and stirring the suspension increases, and energy dissipation in the form of heat increases [4].

In results, the smaller the particle size and the higher density of the suspension that needs to be ground, the more energy is needed to conduct the process and the more heat will be released.

Acknowledgements. The authors would like thanks the perfumery and cosmetics firm "Astra Cosmetic" (Kyiv, Ukraine) for its practice help and transmitted experience. 


\section{- Processes and Equipment -}

\section{References}

1. Chen Y., Lian X., Zheng S. (2015), Research on superfine grinding process and kinetics of calcined black talc in planetary mill, Procedia Ingineering, 102, pp. 379-387.

2. Drögemeier R., Leschonski K. (1994), Comminution, Elsevier.

3. EXAKT Technologies, Inc., Available at: https://www.exakt.de/de/startseite.html.

4. Hrininh K., Gubenia, O., Dimitrov TS. (2018), Osobennosti sverkhtonkogo izmel'cheniya mokrym sposobom v bisernykh mel'nitsakh, 16 International Scientific and Technical Conference «Science for education, production, economics», January 2527, 2018, Best Sprint, Minsk, pp. 303-307.

5. Loh Z.H., Samanta A. K., Heng P.W.S. (2015), Overview of milling technigues for improving the solubility of poorly water-soluble drugs, Asian Journal of Pharmaceutical Science, 10, pp. 255-274.

6. Kanda Y., Kotake N. (2007), Handbook of Powder Technology. Elsevier.

7. Mende S., Rappl M. (2014), Mill performance matched to the task. Throughput enhanced by optimising cooling and disc configuration, European Coatings Journal, 12, pp. 8891.

8. Mende S., Stenger F., Peukert W., Schwedes J. (2013), Mechanical production and stabilization of submicron particles in stirred media mills, Powder technology, 132, pp. 64-73.

9. Nakach M., Authelin J., Agut C. (2017), New Approach and Practical Modelling of Bead Milling Process for the Manufacturing of Nanocrystalline Suspensions, Journal of Pharmaceutical Sciences, 106(7), pp. 1889-1904.

10. Ohnishi O., Suzuki H., Uhlmann E., Schröer N. (2015), Handbook of Ceramics Grinding and Polishing, William Andrew Applied Science Publishers.

11. Postma P.R., Suarez-Garcia E., Safi C., Yonathan K., Oliveiri G., Barbosa M.J., Wijffels R.H., Eppink M.H.M. (2017), Energy efficient bead milling of microalgae: Effect of bead size on disintegration and release of proteins and carbohydrates, Bioresource Technology, 224, pp. 670-679.

12. Rowe W.B. (2014), Principles of Modern Grinding Technology, William Andrew Applied Science Publisher.

13. Salenko YU. (2008), Obladnannya dlya podribnennya materialiv: drobarki ta mlini. Kremenchuk: KDPU.

14. Stephen Miranda (2011), Using an agitator bead mill for nanoparticle dispersion and comminution, Nanotechnology, 11. 